\title{
Juan Octavio Prenz (1932-2019)
}

Juan Octavio Prenz nació en 1932 en Argentina en el seno de una familia de inmigrantes istrianos. Esta doble proveniencia europeoamericana le dotó de una especial sensibilidad y marcó de un modo decisivo su trayectoria personal, profesional y literaria, cuyo punto de convergencia fue el de fomentar vínculos

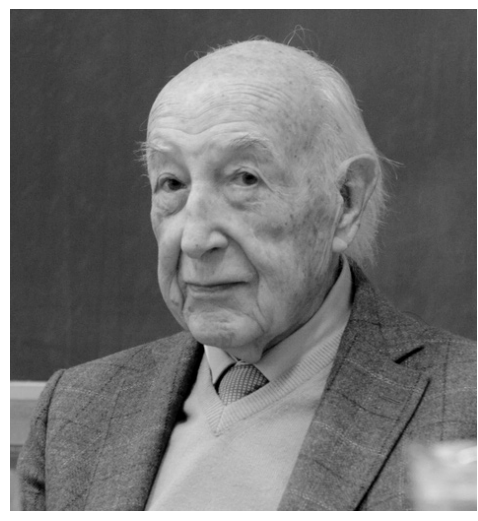
entre las múltiples culturas e identidades de los dos lados del océano: la argentina, la yugoslava, la istriana, la italiana, la centroeuropea y también la eslovena. Entre 1962 y 1967 pasó una primera estancia en Belgrado, donde encontró acogida en el mundo de intelectuales y poetas yugoslavos y a donde volvió con su familia en 1975, huyendo de la dictadura en Argentina. Fue profesor de Literatura Española e Hispanoamericana en la universidad de la capital yugoslava, compaginando su labor académica con la traducción, principalmente de la poesía contemporánea serbia, croata y macedonia. En 1979 se asentó definitivamente en Trieste y fue, hasta su jubilación, profesor en la Universidad de Trieste. A lo largo de sus casi cinco décadas de permanencia en Europa, no dejó de visitar su país de nacimiento cada año.

El profesor Prenz se ha convertido en una de las figuras clave de los inicios de los estudios hispánicos en la Facultad de Filosofía y Letras de la Universidad de Ljubljana, dado que fue el primer profesor de Literatura Española e Hispanoamericana en el Departamento de las Lenguas y Literaturas romances. Durante diez años, desde la fundación de las cátedras de Lingüística y de Literaturas Española e Hispanoamericana en el año 1981 hasta el año 1991, venía de Trieste a impartir clases a las primeras generaciones de estudiantes de español.

A quienes tuvimos el privilegio de atender sus clases en aquellos años pioneros, Juan Octavio Prenz, o simplemente Prenz, nos inculcó para siempre la pasión por explorar el vertiginoso universo literario en lengua castellana. Su vasto conocimiento de la literatura y el sincero amor que profesaba por todas sus vertientes se expandían más allá del discurso académico. Sabía acercarnos con toda naturalidad 
los fenómenos de los tiempos y lugares más remotos, desde las intrigantes jarchas hasta las extraordinarias manifestaciones de la escritura hispanoamericana reciente; adoptaba la idiosincracia y el arte de los poetas y escritores y nos invitaba a acompañarle a sus mundos ficticios por los que transitaba con soltura, ingenio y plena libertad. Dando riendas sueltas a su innato don de contar historias, no dejaba de obsequiar su auditorio con detalles, comentarios y anécdotas que envolvían el ambiente del aula en una suerte de ficcionalidad sui generis.

No sorprende que el arte de Juan Octavio Prenz no se limitara únicamente a contar historias, sino que iba mano a mano con el de crearlas. Es autor de varios cuentos y novelas, entre ellas El señor Kreck (2006) y Sólo los árboles tienen raíces (2013), este último - un homenaje a la condición humana de los inmigrantes colmado de humor irónico y ternura y llevado a cabo en un feliz engranaje de tradiciones literarias centroeuropeas y la gran narrativa hispanoamericana- galardonado en 2019 con el prestigioso premio internacional Nonino. No menos significativa es su voz poética de la que dan fe varios poemarios. Para uno de ellos, La Santa Pinta de la Niña María, le fue otorgado en 1992 el premio Casa de las Américas. Traducida al esloveno se publicó la antología Prostodušne malenkosti (Libertades minimas, 2003).

De especial relevancia para el entorno literario esloveno resultan sus traducciones de poetas eslovenos modernos y contemporáneos al castellano, entre otros Bor, Kocbek, Fritz, Grafenauer, Jesih, Kravos, Novak, Zlobec, Šalamun y el poeta esloveno por antonomasia, France Prešeren (Cantos, 2003).

El profesor Prenz mantuvo estrecha amistad con nuestro departamento también después de dejar de dar clases en 1991. Durante los últimos treinta años siguió honrando y alegrándonos con sus visitas. Fue miembro del Consejo de redacción de la revista Verba Hispanica desde su primer volumen en 1991, y después de 2009 miembro honorario, junto con el cofundador de la revista, el difunto profesor Mitja Skubic.

Nuestro último encuentro tuvo lugar el 19 de marzo de 2019 con ocasión de la publicación en esloveno de su última novela Sólo los árboles tienen raíces. En la misma aula en que lo escuchábamos hace décadas, volvió a seducir a un público nuevo con la misma elegancia de hombre discreto, afectuoso y generoso, dejando grabada en los corazones y la memoria de todos su imagen de ciudadano del mundo capaz de sentirse en casa en todas partes sin echar raíces en ninguna, ya que, según afirmaba, siempre prefirió tener alas. 